\title{
Analysis on Mechanism of Action of Reversed Transmission of the Pres- sure on Adjustment of the Structure of Coal Production and Consumption in China
}

\author{
Li Shuang ${ }^{1, *}$, Yao Wang ${ }^{2}$ and Tang Yanyan ${ }^{1}$ \\ ${ }^{1}$ Management School, China University Of Mining And Technology, Xuzhou, 221116, China; ${ }^{2}$ School of Business, Hohai \\ University, Nanjing, 200098, China
}

\begin{abstract}
The survival and development of coal industry had reached a point where its very existence was at stake in the context of overcapacity and haze siege. For solving the problems of over capacity of coal and realizing transformation of coal consumption structure, this paper discussed various mechanisms of action, which forced coal industry in China to trend toward de-capacity and coal consumption transformation and upgrade guided by marketing tools or government's policies. The core innovation is to carry out the governance mechanism of environment pollution policy tools. The new part compared with previous work is finding that, different policy tools selection will cause different distribution effects and make the burdens of polluters consuming coal, victims and the society never stop. On the one hand it required the market mechanism of supply and demand to force de-capacity in coal industry in China and to change or even remodel operating rules in coal industry; on the other hand it made the polluters consuming coal undertake blowdown cost through the government or marketing tools so that the scientific regulation mechanism could play a decisive role in coal production and consumption.
\end{abstract}

Keywords: Coal consumption structure, over capacity of coal, policy tools, supply and demand mechanism.

\section{INTRODUCTION}

As main primary energy in China, coal always accounts for approximately $70 \%$ to $75 \%$ in production and consumption structure of China primary energies. Coal industry is facing contradictions and problems such as extensive coal production and consumption way, pollution of the environment during use of coal, short-term coal over capacity and so on, although coal industry is a strong support for steady development of national economy and society. Economic growth will cause wealth increase and a lot of resources consumption. There may be two consequences as "the cost of growth", i.e. energy depletion (The global energy consumption is increasing at an average rate of $3 \%$ in recent 100 years. The potential threat of "economic shock" may be caused due to depletion of non-renewable energies such as coal) and environment pollution as well as ecological damage (consumption of large amount of carbon-based energy causes greenhouse effect, environment deterioration and persistent degradation of the global ecological system), which makes that the whole world is suffering from more serious energy and environment crisis.

The core target of the paper is to deal with the issue of overcapacity of coal and to realize transformation of coal consumption structure guiding by marketing tool or government policies. The key is to form effective "forced" mechanism and to make the scientific regulation mechanism play a decisive role in coal production and consumption. From this point of view, the paper discusses various mechanisms of action in forcing de-capacity and coal consumption transformation \& upgrade of China coal industry in the paper.

\section{LITERATURE REVIEW}

\subsection{Forcing Mechanism and Positioning of Economic Transformation and Upgrade}

The forcing mechanism includes not only constraints of marketing mechanism, but also policies and laws oriented constraints, i.e. a series of mutual influences and interaction occurred centrally in a period relatively concentrated as well as the development orientation having internal consistency. Economic transformation and upgrade refers to update of economic system, change of economic growth pattern, improvement of economic structure and transformation of industry development mode.

The environment problem resulted from coal production and consumption has "externality", i.e. enterprise (individual) income is unequal to social benefit. In this case, it is impossible for the market to make good the defect without intervention of the government. Thus, it will result in "market failure". This is Pigou's famous externality theory (Pigou, 1932) [1], which provides an ideal for economic analysis in order to solve coal production and consumption issue, and works also as a reasonable theoretical basis for emission control of the government. However, in many 
cases, unclear property right is the cause for the externality to result in improper resource configuration.

\subsection{Tools Selection of the "Forced" Mechanism}

Many scholars who conduct research in the "forced" mechanism field think that, many applications of policy tools mainly focus on constraints of two types of tools, i.e. standards and taxes. In fact, there are also many other policy tools such as "marketing tool" and "government commands control tool". The two types of tools realize balance although the classification is a little simple. Government control tool requires the support of economic development. Therefore, the marketing tools such as industrial standard, emission targets, Discharge permit and so on are optimal options in many scenarios.

However, there are also some scholars consider that, policy tool can be subdivided into economic incentive (i.e. the carrot policy), legal tool (i.e. big stick policy) and information tool (i.e. preaching policy) (Bemelmans Videc, Rist and Vedung, 1998) [2] and that it can be further divided into tools relevant to substance, organization, law and information (Lundqvist, 2000) [3]. However, no tool is perfect. Each one needs to be utilized comprehensively based on different industries, economic and political environments.

In the 1990s, OECD carried out relatively systematic summarization on policy tools of structure transformation. In the summarization, it was considered that policy tools included command control (e.g. direct control), applications of economic means or market mechanism, persuasive means (i.e. the method using education, information spreading, training as well as social stress, discussion and "moralization" method of other forms).

Portney and Stevens (2000) [4] thought that, even all environmental policies were expressly or implicitly composed of two parts, i.e. exact overall goal (general or special goal, e.g. air quality level or the maximum limit of an emission level) and the means or tools for reaching the goal. Corresponding transmission mechanism would also be selected in order to realize the goal. They pointed out that, legal means, intervention, incentives, centralized control and decentralized control method are the fundamental options faced by environment control.

The research conducted by Chinese scholars, by contrast, was concentrated on policy targets, means, mechanisms and evolution of structure transformation and upgrade. In light of policy analysis, Song Guojun and others (2008) [5] thought that, the general policy mode included responsibility mechanism of relevant people, policy targets, policy framework, policy means, decision-making mechanism, management mechanism, policy evaluation and other elements. Zhang Kunmin (2007) [6] and others carried out research on formation, evolution and characteristics of China environment policy and summarized structure transformation \& upgrade means that commonly used at present in China, which included command control means, market economy means, voluntary action, public participation and etc.

\subsection{The Ways for Realization of Transformation and Upgrade}

Coase pointed out in The Problem of Social Cost that, the party concerned could carry out "internalization" of external effects by negotiation, bargaining and in other ways, provided that the property right was defined clearly and the transaction cost was low enough. (Coase, 1960) [7]. The demand situation of economic system for scarce ecological resources would be changed with the variation of economic structure, improvement of resources utilization rate, change of cost structure, sustainable and affordable energy services [8] and improvement of production technology. It was considered that the latter three factors were driven by the supply $\&$ demand and price. In some cases, it included also replacement of scarce resources and introduction of clean production technology.

\section{MECHANISM OF ACTION OF DE-CAPACITY IN COAL PRODUCTION: ANALYSIS ON MARKET SUPPLY \& DEMAND THEORY}

In recent two years, continued weakness of China coal industry is closely related to excessive growth and release of coal production capacity. In the "ten golden years" of coal industry development, the overall demands in coal market is relatively tense, which to a large extent stimulates investment growth in coal industry and causes rapid increase of the supply of domestic coal market. While the demands of downstream industries decrease, the issue of excess capacity appears gradually, which results in imbalance between supply and demand in domestic coal market.

It analyzes over capacity of coal production process from the point of view of enterprise cost internalization or externalization in this paper. At present, there are many coal enterprises who invest blindly and expand production capacity and scale regardless of cost. As a consequence, there is mass stock of coal. This has a great relationship with the special economic mode dominated by local government of China. Local government externalizes a large portion of internal cost of enterprise (e.g. externalization of capital cost) by utilizing their abilities of control elements. Indirect financing mode but not capital market is dominant in China, which means that it is a financial monopoly and financial control right since there is generally nepotism between most of the local governments and commercial banks. In the past "ten golden years" in coal industry, it was unnecessary to worry about fund if only the coal construction projects are encouraged by the government. From this point of view, fund availability, especially that of state owned enterprises is another important reason for impulsive investment of state owned enterprises. Secondly, it is because of so called externalization of environment cost. Many enterprises basically don't take environmental protection standards or various pollution indexes into consideration. The implementation of a project will be speeded up regardless of environment cost provided that the project invested can benefit them, increase GDP for local government and create tax revenue. The cost of these elements shall be borne by enterprises themselves originally, but now it is paid by the government and the public. As direct consequences, many coal enterprises, especially state 
owned enterprises will invest without consideration of cost and benefits as long as the rate of cost digestion is bigger than the extent of benefit decline, i.e. as long as it is a profit-making enterprise. In this respect, this is the main cause for over capacity in China coal industry at present. Therefore, the reason for existing over capacity in China coal industry can be analyzed intuitively from the point of view of cost benefit.

Coal industry is competitive. "Forced" marketing mechanism refers to taking coal reserves of natural resources, social and environment spill cost into overall consideration. When external cost is internalized, prices of its products will rise with it. In normal case, the demand of final products will decrease, which can be interpreted by conventional economic theory. However, the over capacity issue in China coal industry mainly aims at demands. At present, there is no sharp increase in coal supply. The newly-increased production capacity each year is also kept at a steady speed, but the drop in demand of coal is more serious. All of these aggravates over capacity of coal production.

Assume the production curve is horizontal to facilitate analysis. It means that the marginal cost of production will not change with the variation of output. The demand curve of energy will change from state A on the left to state B on the right due to the change of energy consumption demand caused by economic growth. In this paper, it assumes that the industrial production function is $\mathrm{P} 1$ at state $\mathrm{A}$ and its corresponding output is Q1. Internalization of external cost will cause rise of production cost and the supply curve will move from $\mathrm{P} 1$ to $\mathrm{P} 2$. When the output remains unchanged, the cost of coal industry will increase as shown in dashed area $(a+b+c)$ in the Figure. The area of $d+e+f$ part corresponds to state $\mathrm{B}$.

Decrease extent of output depends on steep degree of demand curve. Even though the coal production in 2012 increased only $130,000,000 \mathrm{t}$ compared with that of 2011 , it was still less than the increment of approximately $300,000,000 \mathrm{t}$ in previous three years. The sharp decline of demands made the supply increment in 2012 a big burden in China coal industry. The production in coal industry only drops from Q1 to Q2 at state A. If the demand is more flexible, the production at state $\mathrm{B}$ along relatively smooth demand curve will decrease from X1 to X2. Obviously, the decline of production is bigger than that at state A. In fact, the true cost increases at state $\mathrm{A}$ and state $\mathrm{B}$ are equivalent respectively to the areas of $\mathrm{a}+\mathrm{b}$ part in following Fig. (1A) and $\mathrm{d}+\mathrm{e}$ part in following Fig. (1B). The production adjustment in coal industry is more obvious at state $\mathrm{B}$ and the effect of "forced" market mechanism on coal production will be reflected.

Further interpretation can also be made by Fig. (1) for distribution situation of internalization of external cost. At initial stage, coal enterprises will bear additional cost increased in the industry, but the determination of the party bearing the final cost will depend on the process that how the cost increased is transferred to shareholders and buyers. The value of product cost shall cause rise of price at state A and B. However, it depends on the reaction of coal purchaser. The buyer will purchase coal products like before at state $\mathrm{A}$ and no obvious adjustment has been resulted from production reduction. Therefore, there is not much impact on shareholders of coal industry at the state. While at state $B$, the same price increment will result in more substantial coal production reduction. If price of the product rises, the purchaser will change to buy other substitute goods. It is unnecessary for the buyer to bear any burden due to price rise. However, large capacity adjustment and industry fluctuations are caused in coal industry at the state. Further investment on coal industry will be decreased by shareholders, the production scale begins to shrink and over capacity starts to fade; even workers of production line will change to work in other departments from coal mining sector.
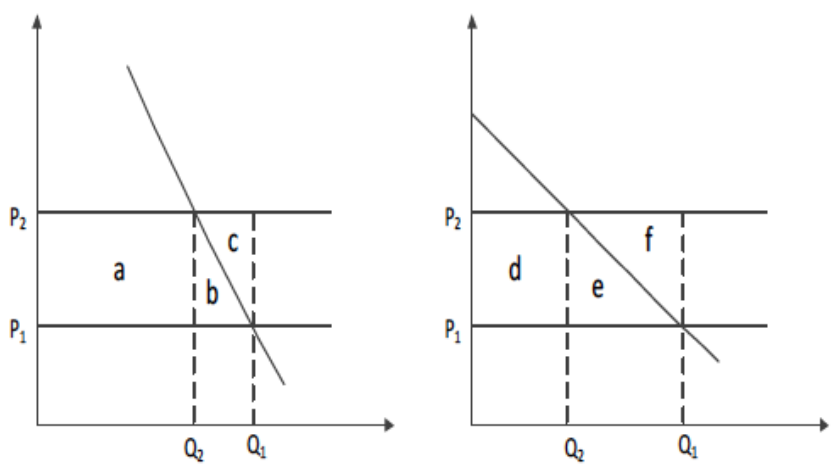

Fig. (1). Coal production capacity adjustment under "forced" mechanism.

\section{MECHANISM OF ACTION OF TRANSFORMA- TION AND UPGRADE IN COAL CONSUMPTION PROCESS: ANALYSIS ON COST-BENEFIT THE- ORY}

Since the beginning of 2013 , there are severe haze in the middle east of China, especially in Beijing, Tianjin, $\mathrm{Xi}$ 'an and other megacities where the haze phenomenon is very serious. There are many causes for the haze and the main ones are automobiles exhaust emission, urban construction pollution, coal consumption emissions and etc. Reduction of coal consumption has become the most difficult issue during haze governance process due to the contribution of coal to energy consumption and its relatively low cost, which is precisely the problem we need to face.

As we all know, half of coal in the world is burned in China. Most of the emissions of sulfur dioxide, nitrogen oxide and smoke in China are from consumption of coal. The coal consumption of China in 2013 accounts for $66 \%$ in primary energies consumption while the coal consumptions in the U.S. and in Japan are always kept at around $25 \%$ in their primary energies consumption. About one half is used for power generation in China coal consumption. Current coal-fired power generation emission reduction technology has been quite mature. However, the annual discharge value is still surprising since the consumption base of coal is huge. The remaining coal consumption in China is basically used for industrial manufacturing and heating except power generation. The mature degree of emission reduction technology and efficiency of the two is far less than that of coal-fired power generation process. 
Dust treatment in other industrial departments is still very poor. The annual dust emission of the several large coal consumers including electric heating, iron \& steel and mineral products accounts for approximately $70 \%$ in the emissions of the state. There shall be no big problem for substitution of coal in large scale. The difficulty is how to realize low-cost replacement. At present, it is relatively difficult yet to make the price of clean energy have comparable competiveness with that of coal. One of the key points of haze governance is cost apportionments. The public prefers to pay for automobile exhaust which is visible but lacks willingness of paying for invisible coal exhaust. How to make the polluters consuming coal undertake blowdown cost through government or marketing tools has become the critical point of future system design.

Different policy tools selection will cause different distribution effects and make the burdens of polluters consuming coal, victims and the society never stop. Different policy tools will result in different cost distribution consequences, of which the policy dominated by efficiency stresses total cost of pollution reduction; the senior management of enterprise polluters cares more about their own performance and average market level, i.e. the effects of cost distribution on the whole industry and the influences of cost distribution on themselves. Marketing policy tools will make the enterprise having the lowest marginal cost of pollution reduction be willing to take measures to reduce pollution from coal consumption.

In this paper, Fig. (2) discusses the cost distribution situations of coal consumption costs and benefits among all polluters, victims and the society caused by different policy tools through setting of an environment and pollutionreduction cost comparison figure relevant to discharge capacity of coal consumption.

The management of coal consumption enterprises wishes to reduce the pollution level to the optimal level (Q1) from the original Q0. The marginal cost of pollution reduction $(\mathrm{MC} 1)$ at the time is equal to the marginal cost of environment pollution (MC2). The benefits to environment improvement by reduction of discharge capacity is equal to the total area of IV (IV refers to pollution-reduction cost), $\mathrm{V}$ and VI, in which V+VI is net benefit of the society. However, the cost distributions between polluters consuming coal and victims are different when different policy tools are utilized. The area III is the pollution cost without deduction and II+III is Pigou tax while II refers to the fund transferred from the polluters to the society when tax or other market approach is used as policy tool. In the meantime, IV $+\mathrm{V}$ are the fixed subsidies provided by government for pollution enterprises based on per unit of discharge reduction (V refers to the fund transferred from the society to pollution enterprises due to provision of fixed subsidy as per unit discharge reduction). Normally, the total amount of subsidies is designed to be precisely equal to IV or one portion of it.

It demonstrates in following table different distribution situations of costs and benefits when the same pollutionreduction level is realized for coal consumption, that is to say, the discharge capacity is reduced to the social optimal level (Q1) from original Q0. The environmental benefits in each column are the same. The costs borne by the polluters and the society including physical pollution-reduction cost, tax revenue and subsidy payment vary in different conditions.

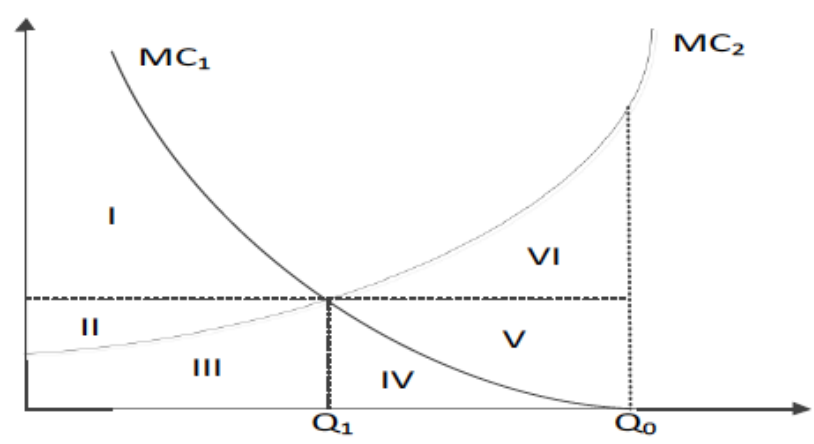

Fig. (2). Costs and benefits related to coal consumption.

In fact, it is an efficiency, welfare and morality issue to decide if the pollution cost shall be borne by the society or the polluters consuming coal. According to Coase (1960), the answer to this question is determined by how to define property right of coal consumption environment. It is a different way for the polluters and victims to share cost burden in each row of above table. When polluters have exclusive ownership on the environment, a victim (the society) has to pay if he wants clean environment without haze or coal cinder.

It is the situation when subsidy is paid to each pollution-reduction unit in Scenario 1 of above table. In this case, the society needs to pay additional subsidy $\mathrm{V}$ to polluters while the polluters not only don't need to pay but can also earn subsidies because of this.

In Scenario 2 of above table, the pollution reduction cost is merely compensation for actual cost IV (or a portion of IV) of pollution reduction, for example, soft loan for pollution-reduction investment.

It indicates the reflection of paying principle to polluters in Scenario 5 of above table. The environment property right belongs to the society (the society can also represents the benefits of pollution victims) in this case and the polluters must pay relevant fees in accordance with market value in order to obtain the right to use the environment. Traditional Pigou tax is the price tool of the type of ownership.

It demonstrates in Scenario of above table that polluters have limited intermediate property right, that is to say, the polluter consuming coal can use relevant environment or resources, but the use can only be continued when some conditions are acceptable. In this case, the polluters must pay some pollution-reduction fee (IV) at reasonable level and shall be responsible for the pollution caused under the level. The cost apportionments in the case can be based on legal form or an agreement reached among all parties.

It shows a concept of intermediate ownership in Scenario 4 of above table. The cost burden will be shared by 
Table 1. Cost-benefit analysis under different policy tools and environmental property rights.

\begin{tabular}{|c|c|c|c|}
\hline Scenario 1 (additional subsidies paid in full to the polluters) & $\mathrm{IV}+\mathrm{V}+\mathrm{VI}$ & $\mathrm{V}$ & $-(\mathrm{IV}+\mathrm{V})$ \\
\hline Scenario 2 (actual cost of pollution reduction paid to polluters) & $\mathrm{IV}+\mathrm{V}+\mathrm{VI}$ & 0 & $-I V$ \\
\hline Scenario 3 (the polluters have limited intermediate property right) & $\mathrm{IV}+\mathrm{V}+\mathrm{VI}$ & $-\mathrm{IV}$ & 0 \\
\hline Scenario 5(the principle of payment by polluters) & $\mathrm{IV}+\mathrm{V}+\mathrm{VI}$ & $-(\mathrm{II}+\mathrm{III}+\mathrm{IV})$ & $\mathrm{II}+\mathrm{III}$ \\
\hline
\end{tabular}

polluters and victims in the case. The polluters must pay pollution-reduction cost and bear pollution costs without deduction, but excluding additional fund transfer (II) related to market price of environment service.

In addition, if coal cannot be substituted in large scale within short term, another focus of haze governance policy shall be how to improve utilization efficiency of coal and to use coal in a cleaner way.

\section{CONCLUSION}

\section{(1) De-capacity relying on market forces}

There is a substantial upper shift of marginal cost curve of coal enterprise due to the increase of spill cost of natural resource, society and environment, which will promote the process of de-capacity in the industry. Adhere to the market orientation and reform direction of market economy; improve and perfect modern coal market system and give full play to the decisive effect of market on resource configuration.

(2) Improving and implementing the governance mechanism of environmental pollution policy tool relying on system

Establish a sound natural resources and environmental resources property right system and use control system; implement the system of paid use of resources and ecological compensation system; build market mechanism which can attract social investment in ecological environment protection; carry out the governance mechanism of environment pollution policy tools; establish and perfect environmental protection management system which can monitor pollutant discharge from coal consumption strictly in order to realize reasonable environment supervision and regulation.

(3) Equal stress is laid on safe \& efficient mining and clean $\&$ efficient utilization of coal relying on technology innovation

Coal industry shall rely on safe \& efficient mining and clean \& efficient utilization in order to maximize resources benefits with the minimum ecological disturbance and to provide support for steady and relatively fast development of Chine economic society. It shall realize the change of coal product from fuel to both the raw material and fuel for safe and efficient coal mining through technology innovation. As for clean \& efficient utilization of coal, it shall care for the achievements of China in coal oil, coal to olefin, coal gas and other coal conversion fields to speed up construction of large-scale clean \& efficient coal conversion projects, to replace effectively oil \& gas resources and to improve environment quality [9].

(4) Reduction of coal consumption and improvement of energy efficiency relying on policy guidance

Energy structure shall be adjusted and coal consumption must be reduced as best as we can under policy guidance of the government. Especially that, direct combustion of coal shall be restrained. It shall improve the technical level for energy utilization, develop co-generation technology of heat and power, encourage cascade utilization of energy and pay high attention to energy saving of coal. It shall perfect energy policy and management system, speed up levying of energy tax, establish standard energy utilization efficiency system, build fair \& open energy market, give full play to the decisive effect of market on energy resources configuration and improvement of energy efficiency through policy adjustment.

\section{CONFLICT OF INTEREST}

The authors confirm that this article content has no conflict of interest.

\section{ACKNOWLEDGEMENTS}

Project supports from National Natural Science Fund (NO.71440005), The Humanities and Social Sciences Research \& Planning Fund Project of The Ministry of Education (12YJA630063), and Social Science Project of Jiangsu Province (10GLB0010) are acknowledged.

\section{REFERENCES}

[1] A. C. Pigou, The Economics of Welfare, $4^{\text {th }}$ Ed., London: Macmillan, 1932.

[2] M.-L. Bemelmans-Videc, R.C. Rist, and E. Vedung, Eds, Carrots, Sticks, and Sermons: Policy Instruments and Their Evaluation, New Brunswick, NJ: Transaction Publishers, 1998.

[3] L.J. Lundqvist, Implementation from above: The Ecology of Sweden New Environmental Governance, Gothenburg, Sweden: University of Gothenburg, Department of Political Science, 2000.

[4] P.R. Portney, and R.N. Stavins, Public Policies for Environmental Protection, $2^{\text {nd }}$ Rev ed., Washington: Resources for the Future Press (RFF Press), 2000.

[5] SongGuojun, et al., Environmental Policy Analysis, Beijing: Chemical Industry Press, 2008. 
[6] K. Zhang, Contemporary Environmental Policy in China: Formation/Characteristics and Evaluation, China Population Resources and Environment, vol. 17, pp. 1-7, 2007.

[7] R.H. Coase, "The problem of social cost", Journal of Law and Economics, vol. 3, pp. 1-44, 1960.
[8] J. Terrapon-Pfaff, C. Dienst, J. König, and W. Ortiz, "A crosssectional review: impacts and sustainability of small-scale renewable energy projects in developing countries", Renewable and Sustainable Energy Reviews, vol. 12, pp.1-10, 2014.

[9] P.H. Riley, "Affordability for sustainable energy development products", Applied Energy, vol. 11, pp. 308-316, 2014.

Received: December 15, 2014

Revised: January 04, 2015

Accepted: February 25, 2015

(C) Shuang et al.; Licensee Bentham Open.

This is an open access article licensed under the terms of the Creative Commons Attribution Non-Commercial License (http://creativecommons.org/licenses/by-nc/3.0/) which permits unrestricted, non-commercial use, distribution and reproduction in any medium, provided the work is properly cited. 